\title{
Designing European Logistic Structures
}

\author{
Jo A.E.E. van Nunen \\ Lorike Hagdorn - van der Meijden \\ Erasmus University Rotterdam
}

This presentation will give an overview of the important trends in international distribution, the challenging opportunities companies are offered, the type of decisions that have to be made and the type of distribution problems that can be solved with the assistance of Decision Support Systems.

In international distribution a lot of fast moving trends are interfering with each other, like:

$\begin{array}{ll}\text { o } & \text { new market area's } \\ \text { o } & \text { changing demands } \\ \text { o } & \text { customer orientation } \\ \text { o } & \text { cost-awareness } \\ \text { o } & \text { new production technologies } \\ \text { o } & \text { information technology } \\ \text { o } & \text { specialization on logistic function } \\ \text { o } & \text { internationalization } \\ \text { o } & \text { reverse logistics } \\ \text { o } & \text { environment }\end{array}$

All these trends give companies the opportunity to develop new distribution concepts to increase their competitive advantage. One of these opportunities is the rationalization of the structure of their international distribution network. Does a company need a national or an international oriented distribution structure? Should they choose for direct or indirect deliveries? How to cope with combining the distribution of different product flows and which delivery times should be realized for which customers are some of the relevant questions. In addition, the information exchange that is required to enable an adequate service is emphasized.

The different subjects will be illustrated by some real life applications. 